\title{
Uji Kelayakan Modul Trigonometri Berbasis Ajaran Tamansiswa
}

\author{
Irham Taufiq1*, Denik Agustito² \\ 1*,2Program Studi Pendidikan Matematika, Universitas Sarjanawiyata Tamansiswa \\ Jalan Batikan UH III/1043, Yogyakarta, D.I. Yogyakarta, Indonesia \\ 1*irham.taufiq@ustjogja.ac.id; 2agustito@ustjogja.ac.id
}

Artikel diterima: 30-11-2020, direvisi: 23-05-2021, diterbitkan: 31-05-2021

\begin{abstract}
Abstrak
Berdasarkan hasil observasi di Prodi Pendidikan Matematika UST Yogyakarta terdapat beberapa masalah pada proses pembelajaran salah satunya yaitu belum tersedianya modul yang berbasis ajaran Tamansiswa. Tujuan penelitian adalah untuk mengembangkan modul Trigonometri berbasis ajaran Tamansiswa dan mencari tahu tingkat kelayakan modul tersebut. Metode penelitian pengembangan dengan model ADDIE yang melalui 5 tahapan yaitu Analysis, Design, Development, Implementation, dan Evaluation. Pada penelitian ini dibatasi sampai tahap Development. Penelitian dilakukan di Prodi Pendidikan Matematika UST. Subjek penelitian adalah mahasiswa yang mengambil mata kuliah Trigonometri pada Semester Gasal Tahun Akademik 2020/2021 yaitu 50 orang. Teknik pengumpulan data menggunakan angket dan wawancara yaitu angket validasi untuk validator ahli materi dan ahli modul. Teknik analisis data secara deskriptif kualitatif dan kuantitatif. Hasil yang dicapai adalah telah berhasil dikembangkan modul Trigonometri berbasis ajaran Tamansiswa. Modul yang dikembangkan ini telah memenuhi kelayakan sesuai dengan hasil validasi ahli modul dan materi dengan hasil validator sangat baik.

Kata Kunci: Ajaran Tamansiswa, Modul, Trigonometri, Uji Kelayakan.
\end{abstract}

\section{Feasibility Test for Tamansiswa Teaching-Based Trigonometry Modules}

\begin{abstract}
Based on the results of observations at the UST Yogyakarta Mathematics Education Study Program, there are several problems in the learning process, one of which is the unavailability of modules based on Tamansiswa teachings. The research objective was to develop a Trigonometry module based on Tamansiswa teachings and to find out the feasibility level of the module. The development research method uses the ADDIE model through 5 stages, namely Analysis, Design, Development, Implementation, and Evaluation. This research is limited to the Development stage. The research was conducted at the UST Mathematics Education Study Program. The research subjects were 50 students taking the Trigonometry course in the Odd Semester of the Academic Year 2020/2021. Data collection techniques used questionnaires and interviews, namely validation questionnaires for material expert validators and module experts. The data analysis technique is descriptive qualitative and quantitative. The result that has been achieved is that the Trigonometry module based on Tamansiswa teachings has been successfully developed. This developed module has met the feasibility by the results of validation by module experts and material with very good validator results.

Keywords: Tamansiswa Teaching, Module, Trigonometry, Feasibility Test.
\end{abstract}




\section{Pendahuluan}

Menurut Ramadhany (2015) pada proses belajar mengajar ada dua aspek penting yaitu pemilihan model pembelajaran dan media pembelajaran yang akan digunakan pada saat pembelajaran berlangsung. Kedua aspek ini saling berkaitan, pemilihan salah satu model pembelajaran tertentu akan mempengaruhi jenis media pembelajaran yang sesuai. Pemilihan dan penggunaan model atau media pembelajaran pasti akan mempertimbangkan dengan kebutuhan peserta didik apakah model dan media pembelajaran sudah sesuai dengan diri peserta didik, sedangkan dalam pemilihan media pembelajaran dapat ditentukan setelah menemukan penggunaan model pembelajaran yang sesuai dengan peserta didik dan materi yang akan disampikan. Media dapat mewakili apa yang kurang mampu diucapkan oleh peserta didik melalui kata-kata atau kalimat tertentu (Maulina, Hikmah, \& Pahamzah, 2019). Bahkan materi yang abstrak dapat dikonkretkan melalui media (Nasution, 2016; Khaidir, 2016).

Namun pada kenyataannya masih banyak pendidik belum dapat memanfaatkan media dan pemilihan model pembelajaran yang sesuai dengan kebutuhan peserta didik (Alwi, 2017). Berdasarkan observasi di Prodi Pendidikan Matematika UST Yogyakarta terdapat beberapa masalah yang ada pada proses pembelajaran. Proses pembelajaran masih menggunakan metode ceramah dan pembelajaran kelompok yang belum terarah. Pembelajaran yang masih terpusat kepada pendidik yang cenderung membuat peserta didik menjadi pasif atau kurang aktif. Serta belum tersedianya modul yang berbasis ajaran Tamansiswa.

Media pembelajaran yang dapat digunakan sebagai bahan ajar adalah modul (Hernandes, 2016). Menurut Laili (2019) modul merupakan salah satu media yang efektif, efisien, dan mengutamakan kemandirian peserta didik. Modul adalah suatu paket pengajaran yang memuat suatu unit konsep dari bahan pengajaran (Ellizar, Hardeli, Beltris, \& Suharni, 2018). Pengajaran modul merupakan suatu usaha penyelenggaraan pembelajaran individual yang memungkinkan peserta didik menguasai suatu unit bahan pelajaran sebelum dia beralih ke unit berikutnya. Penyajian modul tentu sangat diperhatikan, dengan tujuan peserta didik lebih mudah memahami materi, termotivasi, meningkatkan minat belajar, serta mengembangkan potensi-potensi yang ada pada dirinya (Purwati, 2021; Nurhikmayati, 2021)

Menurut Zuriah (2016) dan Hartono (2017), pengembangan bahan ajar berbentuk modul menjadi kebutuhan yang penting karena di dalam modul ada soal dan kunci jawabannya sehingga siswa mengetahui yang benar dan yang salah. Selain itu modul juga membantu perguruan tinggi dalam menciptakan pembelajaran yang bermutu. Penggunaan modul dapat merencanakan kegiatan pembelajaran lebih baik, mandiri, efektif dan dengan hasil (output) yang jelas. Pemanfaatan dan pemberdayaan modul untuk menunjang pembelajaran merupakan suatu kebutuhan untuk meningkatkan penguasaan materi bagi mahasiswa karena materi Trigonometri diajarkan di SMA. 
Ajaran Tamansiswa yang dapat diimplementasikan dalam proses pembelajaran menggunakan modul salah satunya adalah $3 \mathrm{~N}$ yaitu Niteni, Nirokke, Nambahi (Yunianto, 2014). Niteni berarti mengamati/observasi. Nirokke berarti menirukan/mencontoh, terutama praktikpraktik yang terbaik. Nambahi berarti menambahkan, sehingga modul yang dihasilkan lebih baik daripada yang sebelumnya. $3 \mathrm{~N}$ merupakan metode yang sistematik, berseri dan bertahap. Tiap tahapannya tidak boleh saling mendahului supaya memperoleh pengetahuan dan keterampilan yang lengkap (Yunianto, 2014). Sumiati (2019) dan Mas'ad (2019) telah mengembangkan modul berbasis ajaran Ki Hadjar Dewantara tetapi pada materi Geometri. Selain itu, modul Trigonometri juga telah dikembangkan oleh Putra (2016), May (2016), Ismaila (2017), Anggraini (2018), Nurmeidina (2021), dan Setiawan (2021). Namun Sampai saat ini belum ada yang meneliti pengembangan modul Trigonometri berbasis ajaran Tamansiswa.

Penelitian ini merupakan pengembangan modul Trigonometri yang berbasis Tamansiswa dengan menggunakan metode ADDIE dengan tahapan Analysis, Design, dan Development. Hal ini yang menjadi perbedaan dari penelitian pengembangan modul yang dilakukan sebelumnya. Berdasarkan hasil dari validasi yang dilakukan oleh tim ahli, bahwa modul ini dinyatakan layak digunakan dengan kriteria sangat baik. Ini sejalan dengan salah satu penelitian sebelumnya yang dilakukan oleh Sumiati (2019).
Selain itu, diharapkan penelitian ini bisa dijadikan sebagai sumber referensi bagi dosen ketika akan menyusun atau mengembangkan modul perkuliahan yang diampu. Juga sebagai pertimbangan bagaimana seorang pendidik harus memiliki kemampuan dalam mengembangkan modul guna memfasilitasi mahasiswa sehingga tujuan pembelajaran dapat tercapai.

Berdasarkan hasil observasi di prodi pendidikan matematika FKIP UST Yogyakarta bahwa bahan ajar yang digunakan dosen masih berupa buku paket atau ebook dan belum tersedianya modul. Selain itu, pembelajaran Trigonometri di kelas menggunakan metode ceramah di youtube di mana dosen yang aktif dalam menjelaskan materi dan diskusi di SiPedar. lebih dari 30\% mahasiswa yang mengambil mata kuliah Trigonometri tahun akademik 2019/2020 tidak lulus. Berdasarkan uraian tersebut, peneliti tertarik untuk mengembangkan modul Trigonometri berbasis ajaran Tamansiswa. Rumusan masalah penelitian ini adalah bagaimana mengembangkan modul Trigonometri berbasis ajaran tamansiswa dan mengetahui tingkat kelayakan modul tersebut. Sedangkan tujuan penelitian ini yaitu untuk mengembangkan modul trigonometri berbasis ajaran tamansiswa dan mengetahui tingkat kelayakan modul tersebut.

\section{Metode}

Metode penelitian ini menggunakan metode penelitian dan pengembangan, Pada penelitian ini, peneliti telah mengembangkan modul Trigonometri 
berbasis ajaran Tamansiswa. Penelitian ini menggunakan desain one-shot case study. Desain one-shot case study ini dapat disajikan sebagai berikut:

\section{XO}

$X=$ Treatment yang diberikan (variabel independen) berupa angket validasi dan skor hasil angket validasi.

O = Observasi (varibel dependen) berupa modul.

(Nieveen, 2013; Riawan \& Rusimamto, 2019)

Pada penelitian ini, model pengembangan yang digunakan adalah model ADDIE (Analysis, Design, Development, Implementation, and Evaluation). Namun pada penelitian ini dibatasi pada tahap Development. Berikut disajikan bagan model ADDIE (Tegeh, 2012; Anwar, 2019; Wati, Kuswanti, \& Af'idah, 2021) pada Gambar 1 berikut.

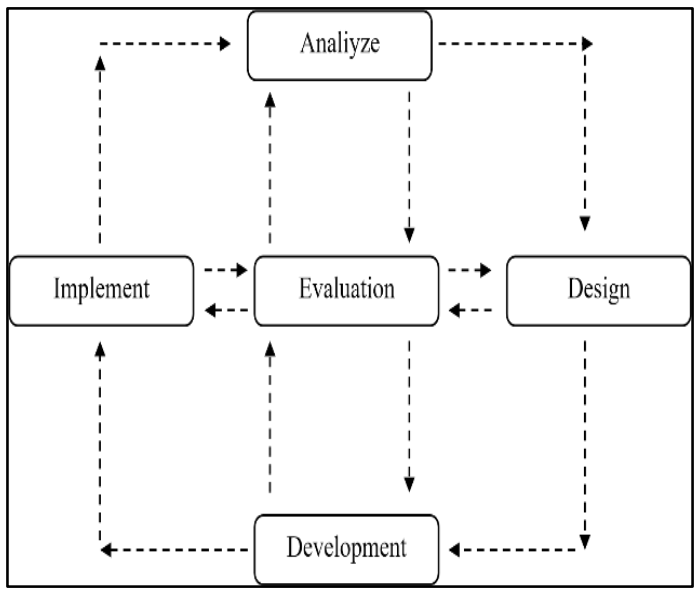

Gambar 1. Model ADDIE.

Prosedur Penelitian observasi dan wawancara untuk mendapatkan gambaran permasalahan yang terjadi di prodi tersebut, studi literatur mengenai Trigonometri dan ajaran Tamansiswa. Tahap design (perancangan produk) ini terdiri dari: Membuat draft modul berbasis ajaran tamansiswa, Mempersiapkan instrumen penelitian yang meliputi angket validasi, media, materi, angket respon peserta didik, dan tes hasil belajar. Development (pengembangan produk) ini terdiri dari modul Trigonometri divalidasi oleh ahli media dan materi. Temuan pada hasil validasi kemudian direvisi.

Penelitian ini dilaksanakan di prodi pendidikan matematika UST dengan subjek penelitian ini adalah mahasiswa prodi pendidikan matematika yang mengambil mata kuliah Trigonometri pada Semester Gasal Tahun Akademik 2020/2021 yang berjumlah 50 orang. Penelitian ini dilaksanakan dari bulan Juli sampai bulan November 2020.

Data kualitatif dalam penelitian ini digunakan berupa tingkatan penilaian kualitas berdasarkan skala Likert. Data kuantitatif dalam penelitian ini diambil dari lembar validasi yang diisi oleh ahli modul dan ahli materi. Teknik pengumpulan data menggunakan teknik validasi produk. Data diolah menggunakan statistika deskriptif. Kemudian mengkonversi skor rata-rata menjadi nilai kualitatif data pada angket kemudian dirangkum dalam bentuk tabel dengan perhitungan skor angket (Sugiyono, 2015).

Instrumen penelitian yang digunakan adalah angket validasi dan lembar wawancara. Modul telah divalidasi oleh ahli materi dan ahli media yaitu tiga orang dosen pendidikan matematika. Skala pengukuran yang digunakan untuk angket validasi media dan materi adalah skala Likert yaitu: Sangat Setuju Sekali (SSS), Setuju Sekali (SS), Setuju (S), Tidak Setuju (TS), dan Sangat Tidak Setuju (STS) (Arcana,2013). 


\section{Hasil dan Pembahasan}

Tahap analisis merupakan tahapan pertama pada penelitian ini. Peneliti melakukan observasi di prodi pendidikan matematika pada pembelajaran trigonometri. Hasil wawancara yang diperoleh dari narasumber adalah pembelajaran trigonometri di kelas menggunakan metode ceramah di youtube dimana dosen yang aktif dalam menjelaskan materi dan diskusi di SiPedar. Pada observasi kelas trigonometri semester gasal tahun akademik 2020/2021, peneliti mengamati sebagian mahasiswa belum memahami materi yang disampaikan karena mahasiswa baru berasal dari SMK ataupun dari sekolah yang berbeda-beda sehingga kedalaman materinya berbeda.

Selanjutnya, Tahap kedua yaitu Design atau perancangan. Peneliti merancang modul dengan membuat peta konsep terlebih dahulu dan apa saja materi yang akan ditampilkan di modul, kemudian menyusun cover, mengetik di Microsoft word. Langkah-langkah yang dilakukan pada tahapan ini adalah membaca referensi, membuat materi dari referensi tersebut, merancang naskah pembelajaran yang memuat kompetensi dasar, indikator pencapaian kompetensi dengan menggunakan Microsoft Word.

Tahap ketiga yaitu Development atau pengembangan. Modul yang telah dibuat diperiksa dan divalidasi oleh ahli media dan materi yaitu dua dosen pendidikan matematika dan satu dosen ketamansiswaan untuk memperoleh masukan terhadap pengembangan media pembelajaran.
Pembuatan modul ini menggunakan Microsoft Word. Materi dibagi menjadi beberapa bagian agar mudah dipahami. Langkah selanjutnya yaitu mengembangkan produk awal/ draft. Draft kebutuhan modul ini disusun berdasarkan hasil analisis kurikulum yang telah dilaksanakan pada tahap sebelumnya. Berikut ini draft kebutuhan modul berbasis ajaran Tamansiswa untuk materi Trigonometri: Halaman Sampul, Halaman Penulis, Kata Pengantar, Daftar Isi, Peta Konsep, Standar Isi, Pengantar, Kegiatan Belajar. Dalam kegiatan belajar berisi tentang kompetensi dasar, tujuan pembelajaran, uraian materi (proses niteni), contoh soal (proses nirokke), latihan soal (proses nambahi). Rangkuman, Tes Formatif, Glosarium, Daftar Pustaka, Kunci Jawaban dan Pembahasan, Profil Penulis.

Materi yang disajikan dalam pengembangan modul matematika berbasis ajaran Tamansiswa adalah materi Trigonometri. Materi tersebut mengacu kepada buku matematika corral dan berbagai sumber referensi lainnya yang sesuai dengan indikator pembelajaran yang telah ditentukan.

Tahap pengembangan yang dilakukan berikutnya adalah membuat modul matematika berbasis ajaran Tamansiswa untuk materi Trigonometri. Penulis menyusun bagian demi bagian dari modul hingga menghasilkan produk awal modul matematika berbasis ajaran Tamansiswa.

Referensi berupa buku atau artikel yang berkaitan dengan pembelajaran berbasis ajaran Tamansiswa, buku-buku paket pelajaran matematika yang berkaitan dengan materi trigonometri. 
Penulisan modul ini dimulai dengan merancang cover modul. Dalam pembuatan cover menggunakan software Corel Draw X7. Halaman penulis berisi tentang informasi modul yaitu judul modul, kurikulum yang digunakan, nama penulis, nama penilai modul, dan aplikasi yang digunakan dalam penyusunan modul.

Kata pengantar berisi tentang peranan modul trigonometri, ucapan terimakasih kepada semua pihak yang membantu pembuatan modul, ungkapan syukur kepada Tuhan, serta harapan yang ditunjukkan kepada pembaca modul.

Daftar isi berisi tentang kerangka materi Trigonometri yang dilengkapi dengan nomor halaman agar pembaca mudah mencari materi yang dikehendaki.

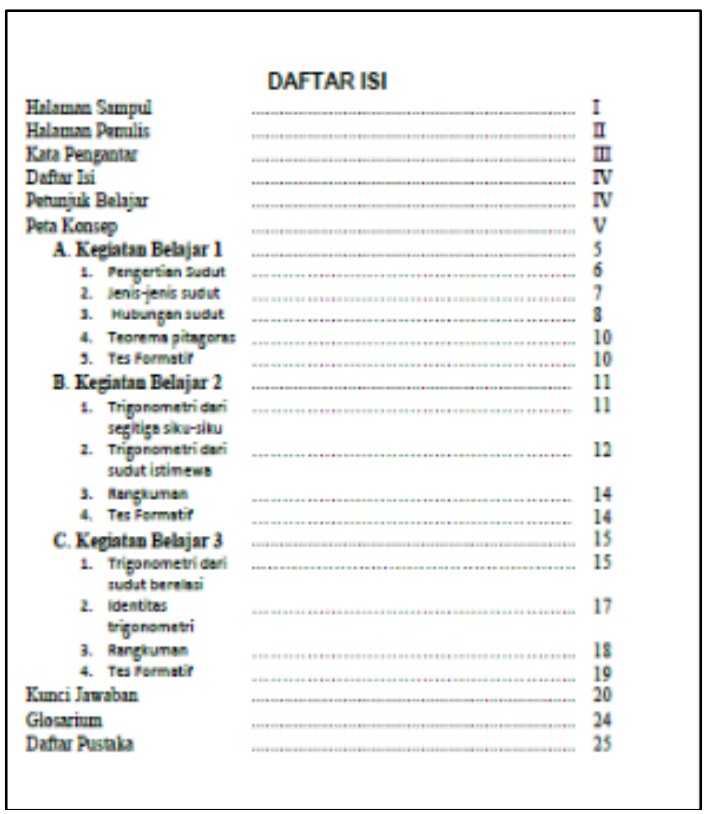

Gambar 2. Daftar Isi Modul.

Peta konsep berisi gambaran yang memaparkan konsep-konsep materi pelajaran yang akan dipelajari dan yang dikuasai oleh mahasiswa dalam keseluruhan kegiatan pembelajaran yang ada pada modul. Fungsi dari peta konsep yaitu untuk mengetahui alur materi yang akan dilaksanakan dalam pembelajaran. Standar isi berisi Kompetensi Inti (KI), Kompetensi Dasar (KD), Indikator Pencapaian Kompetensi (IPK), tujuan pembelajaran, dan petunjuk pembelajaran.

Bagian pengantar diawali dengan sebuah ilustrasi berupa aplikasi trigonometri pada kehidupan sehari-hari yang diharapkan dapat membangkitkan motivasi belajar mahasiswa.

Terdapat 3 buah kegiatan belajar yang berisi materi yang akan dipelajari oleh mahasiswa. Kegiatan belajar terdiri dari sub judul pada modul yang akan dikembangkan, kompetensi dasar, tujuan pembelajaran, uraian materi (proses niteni), contoh soal (proses nirokke), latihan (proses nambahi).

Kompetensi dasar dan tujuan pembelajaran akan dijadikan sebagai acuan untuk menilai ketercapaian hasil pembelajaran peserta didik. Uraian materi berisi tentang pemaparan materi secara singkat dari setiap kegiatan yang ada dalam modul dengan menggunakan ajaran Tamansiswa yang pertama yaitu "Niteni".

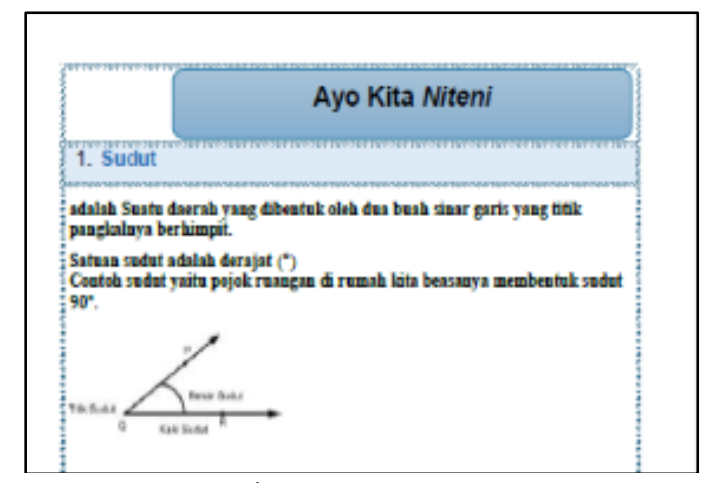

Gambar 3. Proses Niteni.

Ajaran Ki Hadjar Dewantara yang kedua yaitu "Nirokke". Pada setiap kegiatan belajar diperlukan contoh-contoh soal yang 
digunakan untuk menjelaskan dan memperkuat mahasiswa menguasai semua materi yang disajikan.

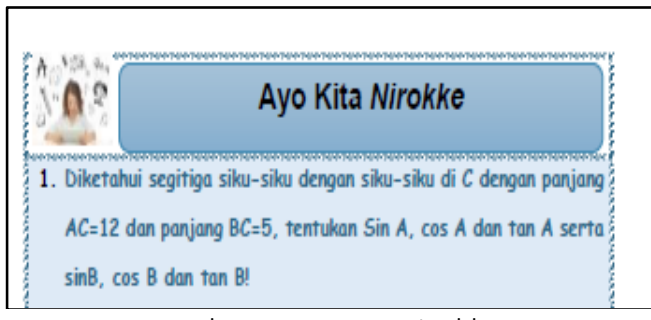

Gambar 4. Proses Nirokke.

Ajaran Tamansiswa yang ketiga yaitu "Nambahi". Proses nambahi digunakan untuk diterapkan pada saat mengerjakan latihan soal. Latihan soal berisi soal-soal dalam bentuk uraian.

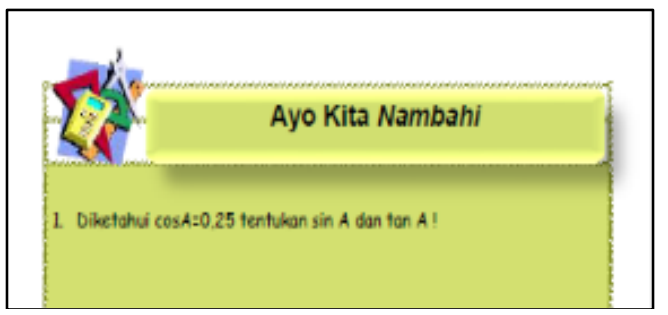

Gambar 5. Proses Nambahi.

Rangkuman berisi tentang ringkasan materi dari uraian materi yang berada di setiap akhir kegiatan belajar dalam modul. Tes formatif berisi soal berbentuk pilihan ganda untuk mengetahui tingkat pemahaman mahasiswa terhadap materi dari setiap kegiatan belajar yang dipelajari pada modul.

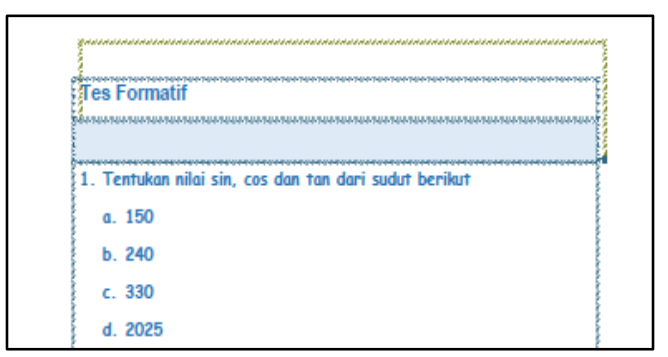

Gambar 6. Tes Formatif.
Glosarium memuat beberapa istilah yang terdapat dalam modul dan disusun secara urut sesuai abjad. Daftar pustaka memuat referensi yang digunakan dalam penyusunan modul. Kunci jawaban berisi kumpulan dari jawaban semua soal-soal latihan dan tes formatif yang ada disetiap kegiatan belajar dalam modul.

Pada tahap Development, peneliti melakukan permohonan validasi kepada ahli media dan materi yang berkompeten dalam bidangnya. Tujuan dari validasi ini adalah memperoleh saran atau masukan dari validator agar menghasilkan media pembelajaran yang layak digunakan.

Ahli yang menilai terdiri dari dosen pendidikan matematika di Universitas Sarjanawiyata Tamansiswa (UST) sebagai validator 1 (V1) dan dosen pendidikan matematika Universitas Tidar sebagai validator (V2). Validator ketiga (V3) adalah Dosen ketamansiswaan di UST.

Tahap validasi adalah tahap untuk mengetahui apakah produk berupa modul pembelajaran yang dikembangkan apakah sudah pantas dan layak digunakan atau belum. Modul trigonometri yang dikembangkan telah divalidasi oleh ahli materi dan modul/ media. Selanjutnya peneliti merevisi modul sesuai saran dan masukan para validator.

Aspek yang dinilai pada validasi materi adalah materi, penyajian materi, Bahasa, 3N (Niteni, Nirokke, Nambahi). Berdasarkan perhitungan diperoleh rata-rata 3,5 dengan kriteria sangat baik. Dan dapat dilihat pada Tabel 1. 
Tabel 1.

Ringkasan Hasil Validasi Materi

\begin{tabular}{|c|c|c|c|c|c|c|}
\hline \multirow{2}{*}{$\begin{array}{l}\mathrm{N} \\
\mathrm{O}\end{array}$} & \multirow{2}{*}{$\begin{array}{c}\text { Aspek } \\
\text { yang } \\
\text { dinilai }\end{array}$} & \multicolumn{3}{|c|}{ Validator } & \multirow{2}{*}{$\begin{array}{c}\text { Rat } \\
\text { a- } \\
\text { rata }\end{array}$} & \multirow[t]{2}{*}{ Kriteria } \\
\hline & & V1 & $\mathrm{V} 2$ & V3 & & \\
\hline 1. & Materi & 3,3 & 3,4 & 3,8 & 3,5 & $\begin{array}{c}\text { Sangat } \\
\text { Baik }\end{array}$ \\
\hline 2. & $\begin{array}{l}\text { Penyaji } \\
\text {-an }\end{array}$ & 3,3 & 3,5 & 3,7 & 3,5 & $\begin{array}{c}\text { Sangat } \\
\text { Baik }\end{array}$ \\
\hline 3. & Bahasa & 3,2 & 3,6 & 3,6 & 3,5 & $\begin{array}{c}\text { Sangat } \\
\text { Baik }\end{array}$ \\
\hline 4. & $\begin{array}{l}3 \mathrm{~N} \\
\text { (Niteni, } \\
\text { Nirokke } \\
\text { 'Namba } \\
\text { hi) }\end{array}$ & 3,1 & 3,6 & 4 & 3,6 & $\begin{array}{c}\text { Sangat } \\
\text { Baik }\end{array}$ \\
\hline \multicolumn{5}{|c|}{ Rata-rata semua komponen } & 3,5 & $\begin{array}{c}\text { Sangat } \\
\text { Baik }\end{array}$ \\
\hline
\end{tabular}

Hasil tersebut juga selaras dengan penelitian Sumiati (2019) dan Ismail (2017). Selain itu, Hasil validasi media/ modul digunakan untuk mengetahui mutu modul tersebut. Adapun komponen validasi media/ modul tersebut meliputi: ukuran modul, desain sampul modul, desain isi modul. Berdasarkan perhitungan tersebut, rata-rata semua komponen adalah 3,6 dengan kriteria sangat baik artinya modul tersebut layak digunakan. Hasilnya dapat dilihat pada Tabel 2.

Tabel 2.

Ringkasan Hasil Validasi Modul

\begin{tabular}{|cccccccc|}
\hline N & Aspek & \multicolumn{3}{c}{ Validator } & Rat & Kriteria \\
\cline { 2 - 5 } o. & $\begin{array}{c}\text { yang } \\
\text { dinilai }\end{array}$ & V1 & V2 & V3 & $\begin{array}{c}\text { a- } \\
\text { rata }\end{array}$ \\
\hline 1 & $\begin{array}{c}\text { Ukuran } \\
\text { Modul }\end{array}$ & 4 & 3 & 4 & 3,7 & $\begin{array}{c}\text { Sangat } \\
\text { Baik }\end{array}$ \\
\hline 2 & $\begin{array}{c}\text { Desain } \\
\text { Sampul } \\
\text { Modul }\end{array}$ & 3,3 & 3,7 & 3,7 & 3,6 & $\begin{array}{c}\text { Sangat } \\
\text { Baik }\end{array}$ \\
\hline 3 & $\begin{array}{c}\text { Desain } \\
\text { Isi } \\
\text { Modul }\end{array}$ & 3,5 & 3,5 & 3,5 & 3,5 & $\begin{array}{c}\text { Sangat } \\
\text { Baik }\end{array}$ \\
\hline & & & & & 3,6 & $\begin{array}{c}\text { Sangat } \\
\text { Bata-rata semua komponen }\end{array}$ \\
\hline
\end{tabular}

Dengan demikian, berdasarkan hasil validasi materi dan modul/ media diperoleh modul trigonometri layak digunakan untuk ke tahap berikutnya dari tahap pengernbangan ADDIE ini.

\section{Penutup}

Kesimpulan dari penelirian ini adalah telah dihasilkan modul trigonometri berbasis ajaran Tamansiswa yang dikembangkan dengan metode ADDIE dengan tahap analysis, design dan development. Berdasarkan hasil validasi ahli modul dan materi, modul ini dinyatakan layak digunakan dengan kriteria sangat baik.

Saran untuk penelitian selanjutnya dapat mengembangkan e-modul agar sesuai dengan kondisi pandemi covid-19 dan mendukung pembelajaran daring.

\section{UCAPAN TERIMA KASIH}

Peneliti mengucapkan terima kasih kepada LP3M UST yang telah membiayai penelitian ini.

\section{Daftar Pustaka}

Alwi, S. (2017). Problematika Guru dalam Pengembangan Media Pembelajaran. Jurnal Itqan, 8(2), 145-167.

Anggraini, N., \& Masykur, R. (2018). Modul

Matematika Berdasarkan Model

Pembelajaran Problem Based Learning Materi Pokok Trigonometri. Desimal: Jurnal Matematika, 1(2), 217-228.

Anwar, M. (2019, October). Development of assessment instruments for chemistry education seminar course at chemical education program of Makassar State University. In Journal of Physics: Conference Series (Vol. 1317, No. 1, p. 012142). IOP Publishing. 
Arcana, I. N. (2013). Bahan Pelatihan Tindakan Kelas Penyusunan Proposal. Surabaya: Unika Widya Mandala.

Ellizar, E., Hardeli, H., Beltris, S., \& Suharni, R. (2018, April). Development of scientific approach based on discovery learning module. In IOP Conference Series: Materials Science and Engineering (Vol. 335, No. 1, p. 012101). IOP Publishing.

Hartono, W., \& Noto, M. S. (2017). Pengembangan Modul Berbasis Penemuan Terbimbing untuk Meningkatkan Kemampuan Matematis pada Perkuliahan Kalkulus Integral. JNPM (Jurnal Nasional Pendidikan Matematika), 1(2), 320-333.

Hernandes, V., Isnaini, M., \& Testiana, G. (2016). Pengembangan Bahan Ajar Matematika Menggunakan Komputer pada Materi Kesebangunan di Kelas IX MTs Negeri 1 Palembang. Mosharafa: Jurnal Pendidikan Matematika, 5(3), 281-292.

Ismail, A. D., Jamil, A. F., \& Putri, O. R. U. (2017). Pengembangan Modul Trigonometri Bercirikan Open-Ended Problem. Jurnal AdMathEdu, 7(1), 1-8.

Khaidir, C. (2016). Pengembangan Buku Ajar Metode Numerik Berbasis Konstruktivisme di IAIN Batusangkar. .Jurnal Ta'dib, 19(1), 67-82.

Laili, I., Ganefri, \& Usmeldi. (2019). Efektivitas Pengembangan E-Modul Project Based Learning Pada Mata Pelajaran Instalasi Motor Listrik. Jurnal Ilmiah Pendidikan dan Pembelajaran, 3(3), 306-315.
Mas'ad, A., Arcana, I. N., \& Taufiq, I. (2019). Modul Geometri Prisma pada Pembelajaran Think Pair Share Berbasis Ajaran Ki Hadjar Dewantara. Jurnal Union: Jurnal Pendidikan Matematika, 7(2), 299-306.

Maulina, U., Hikmah, S., \& Pahamzah, J. (2019). Attractive Learning Media to Cope with Students' Speaking Skills in the Industry 4.0 Using Sparkol Videoscribe. Online Submission, 2(5), 132-140.

May, V., \& Courtney, S. (2016). Developing meaning in trigonometry. Illinois Mathematics Teacher, 63(1), 25-33.

Nasution, A. (2016). Pengembangan Modul Matematika Berbasis Masalah untuk Meningkatkan Kemampuan Pemecahan Masalah Matematik Siswa. Rekognisi: Jurnal Pendidikan dan Kependidikan, 1(1), 47-63.

Nieveen, N., \& Tjeerd, P. (2013). Educational Design Research. Enchede: Netherlands Institute for curriculum development.

Nurhikmayati, I., \& Jatisunda, M. G. (2019). Pengembangan Bahan Ajar Matematika Berbasis Scientific yang Berorientasi pada Kemampuan Berpikir Kritis Matematis Siswa. Mosharafa: Jurnal Pendidikan Matematika, 8(1), 49-60.

Nurmeidina, R., Lazwardi, A., \& Nugroho, A. G. (2021). Pengembangan Modul Trigonometri untuk Mengembangkan Kemampuan Pemecahan Masalah Matematika. Aksioma: Jurnal program studi pendidikan Matematika, 10(1), 15-27. 
Purwati, N. K., \& Erawati, N. K. (2021). Pengembangan Buku Ajar Metode Numerik Berbasis Pembelajaran Kolaboratif. Mosharafa: Jurnal Pendidikan Matematika, 10(1), 37-48.

Putra, R. W. Y., \& Anggraini. (2016). Pengembangan Bahan Ajar Materi Trigonometri Berbantuan Software iMindMap pada Siswa SMA. Al-Jabar: Jurnal Pendidikan Matematika, 7(1), 39 $-47$.

Ramadhany, T., Koryati, D., \& Deskoni. (2015). Analisis Model dan Media Pembelajaran yang Digunakan oleh Guru pada Mata Pelajaran Ekonomi di SMA Se-Kecamatan Inderalaya. Jurnal Profit, 2(1), 34-45.

Riawan, A., \& Rusimamto, P. W. (2019). Pengembangan Perangkat Pembelajaran Kooperatif tipe TGT (Teams Games Tournament) dengan Game Scrabble Pada Kelas XI TEDK Mata Pelajaran Penerapan Rangkaian Elektronika Daya dan Komunikasi di SMKN 5 Surabaya. Jurnal Pendidikan Teknik Elektro, 8(1).

Setiawan, W., Hakim, L. F. N., \& Filiestianto, G. (2021). Pengembangan Bahan Ajar Trigonometri Berbasis Animasi pada Masa Pandemi Covid-19. Jurnal Pembelajaran Matematika Inovatif, 4(2), 435-444.

Sugiyono. (2015). Metodologi Penelitian

Pendidikan. Bandung: Alfabeta.

Sumiati, Arcana, I. N., \& Taufiq, I. (2019).

Modul Geometri Kubus dan Balok pada Pembelajaran Think Pair Share Berbasis Ajaran Ki Hadjar Dewantara. Jurnal Union, 7(3), 329-335.

Tegeh, I. M., \& Kirna, I. M. (2012). Metode Penelitian Pengembangan Pendidikan.
Singarajan: Universitas Pendidikan Ganesha.

Wati, E. K. T., Kuswanti, N., \& Af'idah, N. (2021). RPP Berbasis Model Pembelajaran Kooperatif Tipe STAD Berdasarkan Prosedur Pengembangan ADDIE. Discovery: Jurnal Ilmu Pengetahuan, 6(1), 53-58.

Yunianto, I. K. (2014). Niteni, Niroke, Nambahi sebagai proses berpikir kreatif. Kreatif. Jurnal Desain Komunikasi Visual, 2(2), 121-133.

Zuriah, N., Sunaryo, H., \& Yusuf, N. (2016). IbM Guru dalam Pengembangan Bahan Ajar Kreatif Inovatif Berbasis Potensi Lokal. Jurnal Dedikasi, 13, 39-49.

\section{Riwayat Hidup Penulis}

Irham Taufiq, M.Sc.

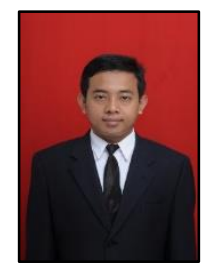

Lahir di Ciamis 7 Agustus 1990, Staf pengajar di prodi pendidikan matematika FKIP UST. Studi S1 Matematika Unsoed Purwokerto lulus tahun 2013; S2 Matematika UGM Yogyakarta tahun Lulus 2015; publikasi terbaik di IOP jornal of physic conference series.

\section{Denik Agustito, M.Sc.}

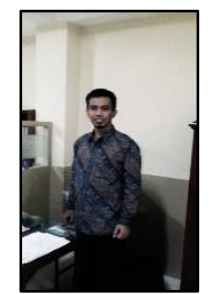

Lahir di Jakarta, 6 Agustus 1984, Staf pengajar di prodi pendidikan matematika FKIP UST. Studi S1 Matematika Unnes Semarang lulus tahun 2006; S2 Matematika UGM Yogyakarta tahun Lulus 2011; publikasi terbaik di IOP jornal of physic conference series. 